\title{
An Isolated, Blood-Perfused, Feline Heart Preparation for Evaluating Pharmacological Interventions During Myocardial Ischemia
}

\author{
W. Mark Vogel* and Benedict R. Lucchesi
}

A preparation is described in which feline hearts were perfused with arterial blood drawn from a blood-donor cat. Ventricular function was measured with a fluidfilled latex balloon within the left ventricle. Left ventricular developed pressure, maximum left ventricular $\mathrm{dP} / \mathrm{dt}$, ventricular compliance, and coronary blood flow changed only slightly during two hours of perfusion at a constant pressure of 75 $\mathrm{mmHg}$. Water, sodium, potassium, and calcium contents, and creatine kinase activity of isolated hearts did not differ from the values obtained for intact hearts from the blood-donor cats. Isolated hearts subjected to 40 minutes of normothermic global ischemia with one hour of reperfusion exhibited significantly decreased contractility, but no change in ventricular compliance. Myocardial water and sodium contents were increased after 40 minutes of ischemia and reperfusion. Hearts subjected to 60 minutes of ischemia with reperfusion exhibited decreases in both contractility and compliance. A prolonged reactive hyperemic response was maintained throughout the hour of reperfusion. Myocardial sodium content increased more than could be accounted for by edema formation; decreases were observed in potassium content and creatine kinase activity while calcium content was increased. The applicability of this model for evaluating the effects of pharmacological interventions on myocardial ischemic injury are discussed.

Key Words: Cardiac contractility; Ventricular compliance; Coronary blood flow; Myocardial electrolytes; Creatine kinase

\section{INTRODUCTION}

During the past decade evidence has accumulated which indicates that the progression of ischemia-induced myocardial changes, from reversible injury to irreversible cell death, can be accelerated or retarded by pharmacological interventions (Hood, 1975). Much of our knowledge of the pathophysiology and pharmacology of myocardial ischemia has been derived from studies of hearts isolated from small laboratory animals and perfused with oxygenated physiological salt solutions. The Langendorff-type preparations have been modified to eject fluid against an afterload

From the Department of Pharmacology and the Upjohn Center for Clinical Pharmacology, University of Michigan Medical School, Ann Arbor, Michigan.

Address requests for reprints to Benedict R. Lucchesi, Ph.D., M.D, Department of Pharmacology, M6322 Medical Science Building I, University of Michigan Medical School, Ann Arbor, Michigan 48109.

* Dr. Vogel's current address is the Cardiac Muscle Research Laboratory, Room 413 Housman Research Bldg., Boston University School of Medicine, $80 \mathrm{E}$. Concord St., Boston, Massachusetts 02118.

Received January 30, 1980; revised and accepted 28 March 1980. 
(Neely et al., 1967) or to perform isovolumic pressure work (Fallen et al., 1967). These preparations are simple and permit good control over the factors affecting cardiac metabolism and mechanical function. Major disadvantages of these models include the lack of adequate colloid osmotic pressure in the perfusate, which can lead to significant edema accumulation and ionic shifts, and also the low oxygen content of the perfusates, which can lead to relative hypoxia and coronary vasodilatation under nominally normal conditions.

Perfusion of the heart with whole blood obviates these problems. Cardiopulmonary by-pass (Reis et al., 1969) and isolated, supported canine heart preparations (Warltier et al., 1976) are available but these can be costly, time consuming, and technically difficult. The purpose of this communication is to describe a simple, isolated, blood-perfused, feline heart preparation, suitable for evaluating effects of pharmacological interventions on myocardial ischemic injury. Methods are described for evaluating the severity of myocardial injury by measurements of contractility, compliance, electrolyte balance, and enzyme content.

\section{METHODS AND MATERIALS}

Hearts from mongrel cats of either sex were isolated and perfused by way of the aorta (retrograde perfusion) with blood drawn from a blood-donor cat, as illustrated in Figure 1.

\section{Preparation of Blood-Donor Cat}

Blood-donor cats $(3-5 \mathrm{~kg}$ ) were anesthetized with $0.7 \mathrm{ml} / \mathrm{kg}$ ip of a dial-urethane solution containing: allobarbital, $100 \mathrm{~g} /$ liter; urethane, $400 \mathrm{~g} /$ /iter; monoethylurea, $400 \mathrm{~g} /$ liter. A femoral artery was isolated and a cannula was advanced to the abdominal aorta to monitor systemic blood pressure. An external jugular vein was isolated, cannulated, and connected through a roller pump (Holter, RE161) to a venous reservoir, that was primed with $30 \mathrm{ml}$ of $0.9 \% \mathrm{NaCl}$ solution. The venous reservoir and the roller pump were connected to an electronic liquid level controller (Cole-Parmer, 7186) which turned off the pump when the blood in the reservoir fell below a specified level. This level was adjusted to maintain the diastolic blood pressure of the blood-donor cat above $75 \mathrm{mmHg}$. A carotid artery was isolated, cannulated, and connected to a second roller pump for withdrawal of arterial blood. The trachea was cannulated and the blood-donor cats were respired with room air, using a positive pressure pump (Harvard, 606). Tidal volume was adjusted to maintain arterial $\mathrm{pH}, \mathrm{PO}_{2}$, and $\mathrm{PCO}_{2}$ within normal limits. Cats were heparinized with 300 units $/ \mathrm{kg}$ iv sodium heparin, and the perfusion apparatus was primed with $20 \mathrm{ml}$ of arterial blood.

\section{Preparation of Isolated Heart}

Cats from which hearts were to be removed $(1.5-2.5 \mathrm{~kg})$, were anesthetized with $35 \mathrm{mg} / \mathrm{kg}$ ip sodium pentobarbital and heparinized with $300 \mathrm{units} / \mathrm{kg}$ iv sodium heparin. The thorax was entered at the sixth left intercostal space. The heart was excised quickly and mounted on the perfusion apparatus. Arterial blood, drawn by the roller pump from the blood-donor cat, was maintained at $37^{\circ} \mathrm{C}$ by a heat ex- 


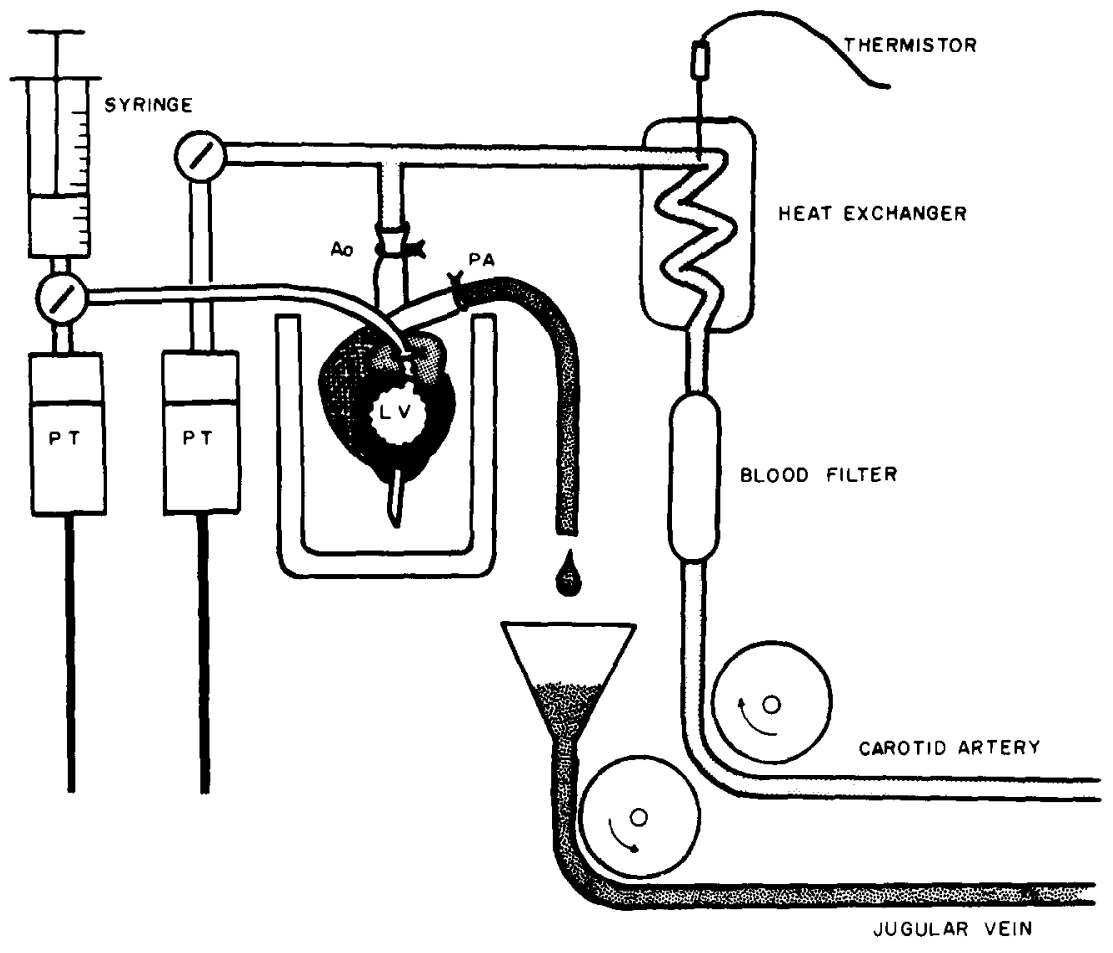

FIGURE 1. Schematic diagram of perfusion apparatus. Isolated heart is perfused via the aorta with arterial blood drawn from a blood-donor cat. $A=$ aorta; $L V=$ left ventricular balloon; $\mathbf{P A}=$ pulmonary artery; $\mathbf{P T}=$ pressure transducer.

changer. Temperature of the blood was monitored continuously with a thermistor probe. Perfusion pressure was recorded with a pressure transducer (Statham, $\mathrm{P} 23 \mathrm{Db}$ ) connected to a side arm of the aortic cannula, and was maintained at 75 $\mathrm{mmHg}$ by manually varying the flow rate of the perfusion pump. A nylon mesh blood filter from a blood transfusion kit was interposed between the perfusion pump and the aortic cannula. When necessary, blood of the cat from which the heart had been removed was added to the venous reservoir to maintain aortic diastolic pressure of the blood-donor cat at $75 \mathrm{mmHg}$.

The vena cava and pulmonary veins were ligated and the pulmonary artery was cannulated to collect the coronary venous effluent, which was returned to the jugular vein of the blood-donor cat via the venous reservoir and roller pump. Coronary blood flow was measured by collecting timed samples from the pulmonary artery cannula. A left ventricular drainage cannula was secured at the apex of the heart with pursestring sutures. Blood collected through the drainage cannula (less than $1 \mathrm{ml} / \mathrm{min}$ ) was retained in the venous reservoir.

Left ventricular volume was controlled with a water-filled latex balloon, placed in the ventricle through the left atrial appendage. The balloon was connected by 
a short length of stiff polyethylene tubing to a syringe and a pressure transducer. Left ventricular pressure and its electronically derived first derivative $(\mathrm{dP} / \mathrm{dt})$ were recorded through this system. Ventricular function curves were inscribed by increasing the volume of the balloon so that ventricular diastolic pressure varied between 0 and $35 \mathrm{mmiHg}$. Ventricular diastolic pressure-volume curves (compliance curves) were constructed from the same data. Each balloon was large enough that no detectable pressure was generated by the balloon itself throughout the volume ranges employed. To eliminate problems due to hysteresis and stress relaxation, function curves were always generated by increasing ventricular diastolic pressure from zero, and pressure was allowed to stabilize after each increase of ventricular balloon volume. Eight to ten minutes were required to generate each function curve.

Isolated hearts were suspended in a water-jacketed vessel maintained at $37^{\circ} \mathrm{C}$. When hearts were subjected to ischemic arrest they were immersed in $0.9 \% \mathrm{NaCl}$ solution. Otherwise the hearts were kept moist by periodically applying $0.9 \% \mathrm{NaCl}$ solution over their surface. An electrocardiogram was recorded from the isolated heart with one electrode attached to the aorta and another to the apex. Hearts were paced electrically from the right atrial appendage at a rate of 150 beats $/ \mathrm{min}$.

\section{Experimental Protocols}

Three groups, each consisting of eight isolated hearts were studied: a control group, a group subjected to 40 minutes of global ischemic arrest, and a group subjected to 60 minutes of ischemia. After being instrumented, each heart was allowed to equilibrate for 60 minutes with the balloon volume adjusted to produce a left ventricular systolic pressure of $150 \mathrm{mmHg}$. At the end of the equilibration period, coronary blood flow was measured with LV diastolic pressure (LVDP) adjusted at zero by deflating the balloon. Ventricular function curves and compliance curves were than generated. Hearts in the two ischemic groups were then made globally ischemic by turning off the perfusion pump and clamping the perfusion cannula. Hearts were not paced during the ischemic period. Balloon volume was held constant at a value that initially produced a LVDP of $15 \mathrm{mmHg}$. At the end of the ischemic period, coronary perfusion was re-instituted at a constant pressure of $75 \mathrm{mmHg}$.

After five minutes of reperfusion hearts that were fibrillating were defibrillated with an injection of $0.05 \mathrm{ml}$ of saturated $\mathrm{KCl}$ solution into the perfusion cannula. The coronary venous blood collected over the next three minutes was discarded so as to prevent recirculation of the injected $\mathrm{KCl}$. LVDP was set at zero and coronary blood flow was measured. The hearts were allowed to recover and measurements of coronary flow, ventricular function, and compliance were repeated 60 minutes after reperfusion.

Control (nonischemic) isolated hearts were perfused for a total of 180 minutes under the equilibration conditions with hourly hemodynamic measurements beginning after the first 60 minutes of equilibration.

\section{Tissue Analysis}

After the final hemodynamic measurements, tissue samples were obtained from the isolated hearts and from the intact hearts of the blood-donor cats. Tissue water, 
sodium, potassium, and calcium content, and myocardial creatine kinase activity were determined. One gram samples from the interventricular septum were minced and placed in tared vessels. Hearts were dried until constant weight was obtained (water content was expressed as $\mathrm{ml} / \mathrm{g}$ dry weight). The dried samples were dissolved in $5 \mathrm{ml}$ of concentrated nitric acid; after appropriate dilutions with distilled water, sodium and potassium contents were determined by flame photometry (Instrumentation Laboratories, 143) and calcium content was determined by atomic absorption spectrometry (Varian Techtron, AA-375). Lanthanum was added to a final concentration of $1 \mathrm{~g} / 100 \mathrm{ml}$ in all calcium samples and standards to suppress interference by phosphate. Ion contents were expressed per gram dry weight. No attempt was made to measure and correct for the extracellular space because reperfusion after ischemia can cause gross changes in sarcolemmal permeability (Hearse, 1977).

For groups of isolated hearts in which water content was significantly elevated (compared to values of the intact hearts from the blood-donor cats) the maximum increase of tissue sodium content that could be attributed to accumulation of edema fluid with the ionic composition of plasma was estimated in the following manner:

$$
\left[\begin{array}{c}
\text { water content } \\
\text { of isolated heart }
\end{array}\left(\frac{\mathrm{ml}}{\mathrm{g}}\right)-\begin{array}{c}
\text { mean water content } \\
\text { of all intact hearts }
\end{array}\left(\frac{\mathrm{ml}}{\mathrm{g}}\right)\right] \times \frac{\mu \text { mole } \mathrm{Na}^{+}}{\mathrm{ml} \mathrm{of} \mathrm{plasma}} .
$$

Two additional $1 \mathrm{~g}$ samples were obtained from the left ventricles of isolated and intact hearts. These samples were homogenized and creatine kinase activity was determined spectrophotometrically by a modification of the method of Kjekshus and Sobel (1970) as described previously (Vogel et al., 1977).

\section{RESULTS}

\section{Contractility, Compliance, and Contracture}

The stability of control isolated hearts, with respect to ventricular pressure development and compliance, and the effects of ischemia on these parameters, are illustrated in Figure 2. Two hours after the initial measurements, the function curve generated in control hearts was depressed showing an $8 \%$ reduction in peak developed pressure ( $p<0.05$, by paired $t$-tests). Ventricular compliance curves in control hearts did not change during the two hours after the initial measurement. In hearts subjected to 40 minutes of ischemia, the final function curve was depressed to values significantly lower than the values obtained for control hearts at a comparable time period ( $p<0.005,40$ minutes final or control final). As in the control hearts, compliance was not changed significantly from the initial values. In hearts subjected to 60 minutes of ischemia there were marked changes in both contractility and compliance. Peak ventricular pulse pressure after recovery was lower than in the 40 minutes ischemic group $(p<0.05)$. After 60 minutes of ischemia, the final compliance curve was shifted toward the left at each point, indicating decreased compliance ( $p<0.01$ for each point by paired $t$-test).

In this isovolumic heart model, function curves generated by plotting left ventricular pulse pressure (LVPP) or maximum $\mathrm{dP} / \mathrm{dt}$ served equally well as indices of contractility. A summary of the changes in LVPP, $d P / d t$, and compliance in the three 


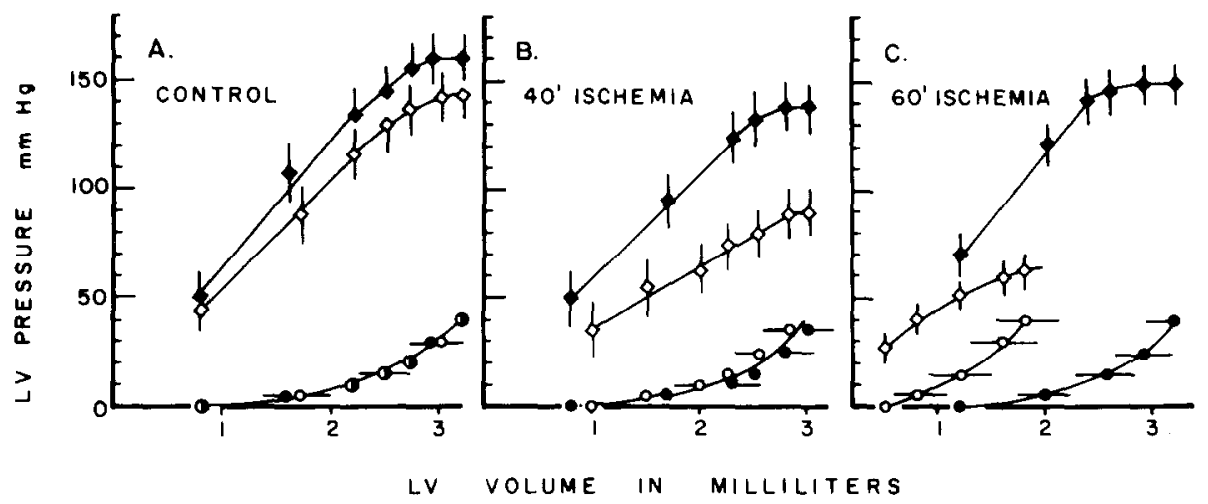

FIGURE 2. Left ventricular function curves were plotted as left ventricular pulse pressure versus LV balioon volume (diamonds); diastolic compliance curves were plotted as left ventricular diastolic pressure versus LV balloon volume (circles). Solid black figures always represent initial value obtained after one hour equilibration; open figures represent final value. (A) In control isolated hearts the function curve generated two hours after equilibration was slightly but significantly depressed compared to the initial values. Compliance in control hearts did not change over the course of the experiment. (B) After 40 minutes of ischemia and one hour of reperfusion, points on the final function curve were significantly depressed compared to the final function curve generated from control isolated hearts. After $\mathbf{4 0}$ minutes of ischemia and one hour of reperfusion, compliance did not change significantly from the initial values. (C) After 60 minutes of ischemia and one hour of reperfusion, the final function curve was significantly depressed compared to the final values from control isolated hearts. The final compliance curve after 60 minutes of ischemia and one hour of reperfusion was shifted significantly toward the left compared either to the initial values for the 60 minute group or the final values for the other two groups.

groups of isolated hearts is presented in Table 1 . The ventricular balloon volume needed to produce a LVDP of $10 \mathrm{mmHg}$ is used as an index of compliance.

The shift of compliance after one hour of ischemia and one hour of reperfusion appears to result from the development of irreversible contracture or rigor during ischemia. During the period of ischemic arrest, resting ventricular pressure (which would correspond to diastolic pressure in the beating heart) increased while ventricular volume remained constant. After 40 minutes of ischemia, resting pressure increased from an initial value of $15 \mathrm{mmHg}$ to a mean value of $27 \pm 3 \mathrm{mmHg}$ for all ischemic hearts ( $p<0.01$ by paired $t$-test). In the hearts that were reperfused at this time, the contracture was reversible; resting pressure increased briefly upon reperfusion, then gradually returned to the initial value during the hour of reperfusion. In the hearts that remained ischemic for 60 minutes, resting pressure continued to increase to a final value of $38 \pm 3 \mathrm{mmHg}(\rho<0.05$ compared to 40 minute value by paired $t$-test). Resting pressure increased further to $46 \pm 5 \mathrm{mmHg}$ during the first five minutes of reperfusion ( $p<0.05$ compared to 60 minute value by paired $t$-test). Five minutes after reperfusion, ventricular volume was decreased until a 
LVDP of zero was obtained to prevent an elevated diastolic pressure from impeding coronary blood flow (Apstein et al., 1977).

\section{Electrical Activity}

In all ischemic hearts, active pressure development ceased within four minutes after perfusion was stopped but electrical activity continued. Heart rate gradually slowed and changed from sinus nodal to ventricular in origin. Electrical arrest, defined as less than 4 beats/min, occurred after an average of $17 \pm 3$ minutes of ischemia. Ventricular fibrillation did not occur in any heart during the ischemic period, while all but one ischemic heart fibrillated upon reperfusion. Potassium chloride injection returned all hearts to normal sinus rhythm.

\section{Coronary Blood Flow}

Coronary blood flow in control isolated hearts decreased slightly during the experiment ( $p<0.05$ by paired $t$-test). In hearts subjected to either 40 or 60 minutes of ischemia, coronary flow was increased during reperfusion compared to flow in control isolated hearts. Coronary flow in isolated hearts subjected to 40 minutes of ischemia returned toward normal values after one hour of reperfusion. After 60

TABLE 1 Cardiodynamic Changes After 40 and 60 Minutes of Ischemia

\begin{tabular}{|c|c|c|c|}
\hline & \multicolumn{3}{|c|}{ PEAK LVPP (mmHg) } \\
\hline & INITIAL & FINAL & $\% \Delta$ \\
\hline Control & $162 \pm 9$ & $147 \pm 8^{a}$ & -8 \\
\hline $40 \mathrm{~min}$ ischemia & $141 \pm 12$ & $92 \pm 8^{a, b, c}$ & -35 \\
\hline \multirow[t]{3}{*}{$60 \mathrm{~min}$ ischemia } & $149 \pm 7$ & $61 \pm 7^{a, b, c}$ & -59 \\
\hline & \multicolumn{3}{|c|}{ PEAK dP/dt (mmHg/sec) } \\
\hline & INITIAL & FINAL & $\% \Delta$ \\
\hline Control & $1971 \pm 118$ & $1868 \pm 115^{a}$ & -5 \\
\hline $40 \mathrm{~min}$ ischemia & $1807 \pm 225$ & $1220 \pm 134^{a, b, c}$ & -32 \\
\hline \multirow[t]{3}{*}{$60 \mathrm{~min}$ ischemia } & $2288 \pm 199$ & $845 \pm 81^{a . b . c}$ & -63 \\
\hline & \multicolumn{3}{|c|}{ LV VOLUME AT LVEDP $=10 \mathrm{mmHg}(\mathrm{ml})$} \\
\hline & INITIALL & FINAL & $\% \Delta$ \\
\hline Control & $2.0 \pm 0.3$ & $2.1 \pm 0^{c}$ & +4 \\
\hline $40 \mathrm{~min}$ ischemia & $2.3 \pm 0.2$ & $2.0 \pm 0.1^{c}$ & -13 \\
\hline $60 \mathrm{~min}$ ischemia & $2.2 \pm 0.2$ & $1.0 \pm 0.3^{a, b, c}$ & -55 \\
\hline
\end{tabular}

\footnotetext{
${ }^{a}$ Indicates significant difference compared to initial value by paired $t$-test.

${ }^{b}$ Indicates significant difference compared to control group by unpaired $t$-test.

' Indicates significant difference between 40 and 60 minute groups by unpaired $t$-test.
} 
minutes of ischemia, the hyperemic response was sustained throughout the one hour recovery period. These results are summarized in Table 2.

\section{Tissue Analysis}

Values for water, electrolyte, and enzyme contents are presented in Table 3 . The values observed for control isolated hearts did not differ significantly in any respect from those observed for intact hearts from the blood-donor cats. In hearts subjected to 40 minutes of ischemia, water content was increased compared to that of control hearts. Sodium content also was increased, but not beyond that which could be attributed to an accumulation of edema fluid with an ionic composition similar to plasma. Calcium content in hearts subjected to 40 minutes of ischemia was slightly higher than in control hearts but this difference was not statistically significant. Potassium content and creatine kinase activity did not differ from the values observed in control isolated hearts.

In hearts subjected to 60 minutes of ischemia, water and sodium contents were elevated compared to the control group. The total increase of sodium was $20 \pm 3$ mmoles/100 g dry weight. Of this, $11 \pm 4$ mmoles/100 $\mathrm{g}$ dry weight could be accounted for by an accumulation of edema fluid, leaving an increase of $9 \pm 3$ mmoles/ $100 \mathrm{~g}$ dry weight which could not be attributed to edema. Potassium content of hearts subjected to 60 minutes of ischemia was decreased by $9 \pm 3$ mmoles $/ 100 \mathrm{~g}$ dry weight when compared to control hearts. Calculations for the effect of accumulated edema fluid did not alter the value for potassium content due to the low concentration of potassium in plasma. Calcium content was elevated markedly in hearts subjected to 60 minutes of ischemia, to values nearly three times those observed in control hearts. Creatine kinase activity in hearts subjected to 60 minutes of ischemia was $31 \%$ less than in control hearts.

\section{DISCUSSION}

The characteristics of the blood-perfused cat heart preparation make this a useful model for studying interventions that might alter the course of ischemic injury. In the absence of an ischemic insult, control isolated hearts demonstrated satisfactory

TABLE 2 Effects of Global Ischemia on Coronary Blood Flow

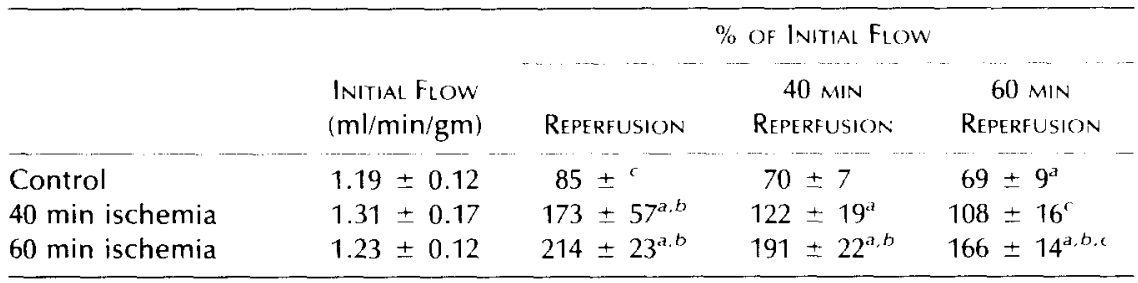

\footnotetext{
${ }^{a}$ Indicates significant difference compared to initial flow by paired $t$-test.

${ }^{b}$ Indicates significant difference from control group by unpaired t-test.

cIndicates significant difference between 40 and 60 minutes ischemia by unpaired t-test.
} 
TABLE 3 Myocardial Water, Electrolyte, and Enzyme Contents

\begin{tabular}{|c|c|c|c|c|c|c|}
\hline & $\begin{array}{c}\text { WaTER } \\
(\mathrm{ml} / \mathrm{g} \text { dry } \mathrm{wt})\end{array}$ & $\begin{array}{c}\text { Sodium } \\
\text { (mmole/ } \\
100 \mathrm{~g} \text { dry wt) }\end{array}$ & $\begin{array}{c}\text { SODIUM } \\
\text { (CORRECTED) } \\
\text { (mmole } / \\
100 \mathrm{~g} \text { dry wt) }\end{array}$ & $\begin{array}{c}\text { Potassium } \\
\text { (mmole/ } \\
100 \mathrm{~g} \text { dry wt) }\end{array}$ & $\begin{array}{l}\text { Calcium } \\
\text { ( } \mu \text { mole' } \\
\text { g dry wt) }\end{array}$ & $\begin{array}{c}\text { CREATINE } \\
\text { KINASE } \\
\text { (I.U./ } \\
\text { mg protein) }\end{array}$ \\
\hline $\begin{array}{l}\text { Blood-donor hearts } \\
\quad(n=18)\end{array}$ & $3.29 \pm 0.05$ & $18 \pm 1$ & $18 \pm 1^{b}$ & $32 \pm 1$ & $8 \pm 1$ & $43 \pm 1$ \\
\hline $\begin{array}{l}\text { Control isolated } \\
\text { hearts }(n=6)\end{array}$ & $3.20 \pm 0.05$ & $19 \pm 2$ & $19 \pm 2^{b}$ & $31 \pm 3$ & $8 \pm 1$ & $43 \pm 1$ \\
\hline $\begin{array}{l}40 \text { min ischemia } \\
\text { isolated hearts } \\
(n=6)\end{array}$ & $3.96 \pm 0.10^{c}$ & $29 \pm 3^{c . d}$ & $19 \pm 3^{d}$ & $31 \pm 2^{d}$ & $11 \pm 2^{d}$ & $39 \pm 5^{d}$ \\
\hline $\begin{array}{l}60 \text { min ischemia } \\
\text { isolated hearts } \\
(n=6)\end{array}$ & $4.04 \pm 0.19^{c}$ & $39 \pm 3^{c d}$ & $28 \pm 2^{c \cdot d}$ & $21 \pm 2^{c, d}$ & $24 \pm 2^{c, d}$ & $30 \pm 2^{c, d}$ \\
\hline
\end{tabular}

a Corrected sodium $=$ total sodium minus sodium content of edema fluid.

"Corrected sodium was not calculated for these hearts.

'Significantly different from control isolated hearts.

${ }^{\prime}$ Significant difference between 40 and 60 minutes of ischemia.

hemodynamic stability, which was comparable to that reported by Neely et al. (1967) for working hearts perfused with a physiological salt solution, or to that of the blood-perfused septum described by Bayliss et al. (1977). The peak developed pressure and $\mathrm{dP} / \mathrm{dt}$ observed in these isolated hearts were similar to values reported by Reis et al. (1969) for dogs on cardiopulmonary by-pass.

Although the cat heart preparation exhibited satisfactory stability of cardiac mechanics, there was a gradual decrease of coronary-blood flow in the control isolated hearts. It seems unlikely that this resulted from microembolization by platelets, air, or denatured proteins, because there was no evidence of ischemic injury in control isolated hearts by analysis of water, electrolyte, or enzyme contents. Despite the gradual decrease of coronary blood flow, the flow rates were within the range of 80 to $120 \mathrm{ml} / \mathrm{min}$ per $100 \mathrm{~g}$ reported for the intact myocardium (Domenech et al., 1969). In contrast, greatly elevated coronary flow rates are required to provide adequate oxygenation of hearts perfused with physiological salt solutions (Neely et al., 1967; Apstein et al., 1977). Such hearts may be near maximal vasodilatation in the control state, which would obscure the effects of ischemia or pharmacological interventions on myocardial blood flow. Indeed, hearts perfused with a salt solution may exhibit a decrease of coronary flow after ischemia (Goldman et al., 1978) rather than the expected hyperemic response that was observed with the blood-perfused model as described in this report. The normal coronary flow responses of this bloodperfused preparation should make it well suited for assessing the effects of drugs and ischemia on global coronary flow.

Another favorable characteristic of this model is the stability of water and electrolyte balance. Lack of adequate colloid osmotic pressure in most perfusion solutions results in considerable edema formation and increases of total myocardial tissue sodium in the absence of any ischemic insult (Nayler and Seabra-Gomez, 1976; 
Rovetto, 1977). Such a shift could lead to difficulty in interpretation of results, particularly with regard to the effects of agents such as mannitol (Weisfeldt et al., 1973), hyaluronidase or the glucocorticoids (Rovetto, 1977) that are reported to retard myocardial edema formation.

The pattern of changes observed after global ischemia in this blood-perfused preparation suggests that that $\mathbf{4 0}$ minutes of ischemia produced largely reversible injury while 60 minutes of ischemia resulted in significant irreversible damage. The only changes observed after an hour of recovery from 40 minutes of ischemia were an incomplete return of contractility and an increase of sodium and water content. After 60 minutes of ischemia hearts exhibited decreased ventricular compliance and a further decrease of contractility. Increases of water and sodium content were accompanied by decreases of potassium content and creatine kinase activity.

The prolonged decrease of contractility after 40 minutes of ischemia need not imply irreversible injury because many hours may be required for full recovery of contractile function after periods of reversible ischemia (Heyndrickx et al., 1975; Weiner et al., 1976). The reversal, during the recovery period, of the increased resting pressure of hearts subjected to $\mathbf{4 0}$ minutes of ischemia indicates that development of contracture during ischemia is not necessarily a sign of irreversible injury. The myocardial contracture which developed during the 60 minute ischemic period was not reversed by reperfusion and resulted in decreased compliance during the hour of reperfusion. This persistent decrease of compliance after 60 minutes of ischemia is characteristic of more severe, perhaps irreversible, injury (MacGregor et al., 1975; Apstein et al., 1977; Hearse et al., 1977). These mechanical changes may be related to the "contraction band necrosis" observed under light and electron microscopy (Reichenbach and Benditt, 1968; Jennings et al., 1969). Because changes of ventricular compliance are characteristic of ischemic injury, the ventricular balloon is an important aspect of this preparation, allowing direct measurement of ventricular compliance.

The accumulation of sodium after 40 minutes of ischemia is probably not indicative of irreversible injury. Potassium depletion did not occur as would be expected if the increase of sodium were due to a marked alteration of the overall permeability of the sarcolemma. Accumulation of sodium after 40 minutes of ischemia was probably due to accumulation of extracellular edema fluid. In a study of ischemia-induced edcma in skeletal muscle, Diana and Laughlin (1974) concluded that edema resulted primarily from an increased capillary hydrostatic pressure due to arteriolar dilatation during the post-ischemic hyperemic response. If a similar mechanism was responsible for the increased water content observed after myocardial ischemia, the edema fluid would have a sodium content similar to an equal volume of plasma water. In the present study, calculations demonstrated that the increase of total myocardial sodium content could be accounted for by an accumulation of edema fluid with an ionic composition similar to plasma.

After 60 minutes of ischemia, total myocardial sodium content increased by more than could be accounted for by an accumulation of edema fluid. This was accompanied by a decrease in potassium content. These data suggest that the electrolyte 
disturbance after 60 minutes of ischemia was due to impaired ion transport or to damage of the sarcolemma, which might indicate irreversible injury. The large increase of calcium content that occurred after 60 minutes of ischemia is also characteristic of irreversible injury (Shen and Jennings, 1972). The excessive calcium accumulation may be partially responsible for the persistent contracture observed in these hearts (Hearse et al., 1977; Henry et al., 1977). Finally, the maintenance of creatine kinase activity after 40 minutes of ischemia and its depletion after 60 minutes of ischemia is further evidence that irreversible injury occurred during 60 minutes of global-ischemic arrest but not during 40 minutes of global-ischemia.

The time course of changes observed in these isolated hearts is similar to that observed in intact dogs subjected to cardiopulmonary by-pass with aortic crossclamping. Such hearts usually tolerate up to 30 minutes of normothermic ischemic arrest quite well, with severe injury occurring after 45 to 60 minutes (Buja et al., 1971; Sarin et al., 1968; Stemmer et al., 1973). In contrast, isolated rat hearts perfused with salt solutions may exhibit severe myocardial injury after 30 minutes or as little as 5 minutes of ischemia or anoxia (Busuttil and George, 1978; Hearse et al., 1977; Nayler et al., 1978).

We have used this model to evaluate the effects of two drugs, methylprednisolone and $\mathrm{N}$-dimethyl propranolol, during 60 minutes of ischemia (Vogel et al., 1978; Vogel et al., 1979). We have administered drugs directly into the aortic perfusion cannula and also intravenously to the blood-donor cat. The latter route allows comparison of drug doses on a $\mathrm{mg} / \mathrm{kg}$ basis. There are both advantages and disadvantages to the fact that drugs may have access to the intact blood-donor circulation. The glucose-insulin-potassium combination, for example, may have direct effects on myocardial glucose utilization as well as indirect effects by suppressing lipolysis and thus decreasing plasma free fatty acid concentrations (Rogers et al., 1976). Both direct and systemic effects could influence the response of the isolated heart in our preparation. This has advantages in determining the possible efficacy of systemically-acting agents, but may raise difficulties in elucidating the precise mechanism of action.

In summary, we have described a simple, isolated, bloody-perfused, feline heart preparation that may serve as a useful model for evaluating the effects of pharmacological agents on the progression of myocardial ischemic injury. Control isolated hearts demonstrated satisfactory hemodynamic performance and stability, and maintained water, electrolyte, and enzyme contents comparable to intact hearts. Normothermic, global-ischemic arrest caused characteristic changes of contractility, ventricular compliance, coronary blood flow, water and electrolyte contents, and in creatine kinase activity during reperfusion. The time course of injury was similar to that reported for intact hearts. It is likely that the changes observed after 60 minutes of ischemia represent irreversible injury and thus can serve as markers for the effects of pharmacological interventions on myocardial viability.

This work was supported by USPHS grant HL-19782-03 and in part by a research grant from the American Heart Foundation. 


\section{REFERENCES}

Apstein CS, Deckelbaum L, Mueller M, Hagopian L, Hood WB, Ir (1977) Graded global ischemia and reperfusion: Cardiac function and lactate metabolism. Circulation $55: 864-872$.

Bayliss CE, Crawford FB, Nsafoah B (1977) The intraventricular septum: An isolated perfused model for assessing myocardial function. Canad / Physiol Pharmacol 55 : 1358-1368.

Buja LM, Levitsky S, Souther SG, Ferrans VJ, Roberts WC, Morrow AG (1971) Acute and chronic effects of normothermic anoxia on canine hearts: Light and electron microscopic evaluation. Circulation 43 (Suppl. 1): 44-50.

Busuttil RW, George WJ (1978) Protective action of methylprednisolone on the isolated perfused rat heart following severe hypoxia. Proc Soc Exp Biol Med $157: 580-583$.

Diana IN, Laughlin MH (1974) Effect of ischemia on capillary pressure and equivalent pore radius in capillaries of the isolated dog hind limb. Circ Res $35: 77-101$.

Domenech RJ, Hoffman JIE, Noble MIM, Saunders KB, Henson JR, Subijanto $S$ (1969) Total and regional coronary blood flow measured by radioactive microspheres in conscious and anesthetized dogs. Circ Res $25: 581-596$.

Fallen EL, Elliot WC, Corlin R (1967) Apparatus for study of ventricular function and metabolism in the isolated perfused rat heart. / App/ Physiol 22:836-839

Goldman RA, Schaff HV, Flaherty JT, Bulkley BH, Brawley RK, Donahoo JS, Gott VL (1978) Failure of methylprednisolone to protect myocardial function or prevent myocardial edema following ischemic cardiac arrest. / Surg Res 24 : 477-487.

Hearse DJ (1977) Reperfusion of ischemic myocardium. I Molec Cell Cardiol 9:605-613.

Hearse DI, Garlick PB, Humphrey SM (1977) ischemic contracture of the myocardium: Mechanisms and prevention. Am / Cardio/ 39 : 986-993.

Henry, PD, Suchleib R, Davis I, Weiss ES, Sobel BE (1977) Myocardial contraclure and accumulation of mitochondrial calcium in ischemic rabbit heart. Am J Physiol 233 : H677-684.

Heyndrickx GR, Millard RW, McRitchie RI, Maroko PR, Vatner SF (1975) Regional myocardial function and electrophysiological alterations after brief coronary artery occlusion in conscious dogs. / Clin Invest 56:978-985.
Hood WB, Ir (1975) Modification of infarct size. Cardiovascular Clinics 7:259-278.

Jennings RB, Sommers HM, Herdson PB, Kaltenbach JP (1969) Ischemic injury of myocardium. Ann NY Acad Sci $156: 61-78$.

Kjekshus JK, Sobel BE (1970) Depressed myocardial creatine phosphokinase activity following experimental myocardial infarction in rabbit. Circ Res $27: 403-414$.

MacGregor DC, Wilson GJ, Tanak S, Holness DE, Lixfeld W, Silver MD, Rubis LJ, Goldstein W, Gunstensen I (1975) Ischemic contracture of the left ventricle: Production and prevention. /. Thorac Cardiovasc Surg 70 : 945-954.

Nayler WG, Seabra-Gomez R (1976) Effect of methylprednisolone sodium succinate on hypoxic heart muscle. Cardiovasc Res 10:349-358.

Nayler WG, Yepez C, Grau A, Slade A (1978) Protective effect of methylprednisolone sodium succinate on the ultrastructure and resting tension of hypoxic heart muscle. Cardiovasc Res 12 : 91-98.

Neely IR, Liebermeister H, Battersby EJ, Morgan HE (1967) Effect of pressure development on oxygen consumption by isolated rat heart. Am / Physiol $212: 804-814$

Reichenbach DD, Benditt EP (1968) Myotibrillar degeneration: A response of the myocardial cell to injury. Arch Pathol 85 : 189-199.

Reis RL, Staroscik RN, Rodgers BM, Enright LP, Morrow AG (1969) Left ventricular function after ischemic cardioplegia. Arch Surg 99: 815-820.

Rogers WJ, Stanley AW, Ir, Breinig JB, MCDaniel HG, Moraski RE, Mantle IA, Russell RO, Ir, Rackley CE (1976) Reduction of hospital mortality rate of acute myocardial infarction with glucose-insulin-potassium infusion. Am Heart / 92 : 441-454.

Rovetto MI (1977) Effect of hyaluronidase and methylprednisolone on myocardial function, glucose metabolism, and coronary flow in the isolated ischemic rat heart. Circ Res $41: 373-377$.

Sarin CL, Hall RW, Ross DN (1968) Effects of extracorporeal circulation on left ventricular function with and without anoxic arrest. I Thorac Cardiovasc Surg 56:395-400.

Shen AC, Jennings RB (1972) Kinetics of calcium accumulation in acute myocardial ischemic injury. Am / Pathol 67: 441-452.

Snedecor CW, Cochran GC (1967) Statistical Methods, 6th Edition, Ames, lowa: lowa State University Press. 
Stemmer EA, McCart P, Stanton WW, Thibault W, Dearden LS, Connolly JE (1973) Functional and structural alterations in the myocardium during aortic cross clamping. I Thorac Cardiovasc Surg $66: 754-767$.

Vogel WM, Zannoni VG, Abrams GD, Lucchesi BR (1977) Inability of methylprednisolone sodium succinate to decrease infarct size or preserve enzyme activity measured 24 hours after coronary occlusion in the dog. Circulation $54: 588-595$.

Vogel WM, Lum D, Lucchesi BR (1979) Methylprednisolone sodium succinate treatment in global ischemia of the cat isolated heart. / Cardiovasc Pharmacol 1 : 53-68.

Vogel WM, Lum D, Romson J, Lucchesi BR (1978)
Protection of globally ischemic cats' hearts by $\mathrm{N}$ dimethyl propranolol (UM-272). Fed Proc 37 : 124.

Warltier DC, Gross GJ, Hardman HF (1976) The isolated supported canine heart: A model for the evaluation of drug effects on regional myocardial blood flow. I Pharmacol Exp Ther 198:420-434.

Weiner, IM, Apstein CS, Arthur JI, Pirzada ГA, Hood WB, Jr (1976) Persistence of myocardial injury following brief periods of coronary occlusion. Cardiovasc Res 10:678-686.

Weisfeldt ML, Scully HE, Selden R, Bellos AG, Powell WJ, Dagget WM (1973) Effect of mannitol on the performance of isolated canine heart after fibrillatory arrest. I Thorac Cardiovasc Surg $66: 290-299$. 